\title{
The Impact of Orthodontic Appliance on Body Weight Changes, Dietary Habits, and Self-Perceived Discomfort in Early Stages of Orthodontic Treatment
}

\author{
Nancy Ajwa ${ }^{1}$, Lamya Makhdoum², Hadeel Alkhateeb², Alanoud Alsaadoun², \\ Samiah Alqutub ${ }^{2} \&$ Hajer Alkhumayes ${ }^{2}$ \\ ${ }^{1}$ Faculty member - Preventive Department/Orthodontic Division, Riyadh Elm University, Riyadh, KSA \\ ${ }^{2}$ Dental Inters, Riyadh Elm University, Riyadh, KSA \\ Correspondence: Nancy Ajwa, Lecturer, Preventive Department/Orthodontic Division, Riyadh Elm University, \\ Riyadh, KSA. Tel: 966-554-804-564. E-mail: nancy.ajwa@gmail.com
}

Received: July 2, 2018 Accepted: July 24, 2018 Online Published: August 1, 2018

doi:10.5539/gjhs.v10n9p11

URL: https://doi.org/10.5539/gjhs.v10n9p11

\begin{abstract}
Aims: To assess and compare the changes in body weight, dietary habits, and pain perception of patient's undergoing orthodontic treatment at the initial stage.

Material and Methods: This was an observational prospective cohort study to assess patient's changes in body weight, dietary habits, and pain perception undergoing orthodontic treatment at the initial stage. Thirty patients who received orthodontic treatment "for the first time" and those who will get comprehensive orthodontic treatment within the age group of 18-30 years old including both genders were included in the study. The weight as well as dietary habits of patients were measured at the initial visit, "prior reserving of any the orthodontic treatment" as (T0). Re-evaluation of patient's weight, dietary habits, and pain perception were re-assessed on the next visit" after fixed orthodontic appliance bonding" as (T1) one month later. The pain, discomfort, and dietary habits changes were evaluated using a validated questionnaire.
\end{abstract}

Results: The mean (SD) patient weight at first and second visit of orthodontic treatment was 67.43 (24.42) and 64.98 (22.7) $\mathrm{kg}$ respectively. The difference in the patient weight between first and second visit was statistically significant. Patients with discomfort and patients who used medication to relieve pain were reported to have more weight loss.

Conclusions: This study confirms the initial loss of weight, pain and discomfort among patients who undergo orthodontic treatments. The findings of this study are of importance among the orthodontic centres and practitioners highlighting the importance of their guidance in structured diet planning and advice after treatment.

Keywords: appliance, orthodontics, weight

\section{Introduction}

Patient seeking orthodontic treatment-usually to improve facial or dental aesthetic (Borzabadi-Farahani, 2011). Recently, patients have greater perception of aesthetics which resulted in increased demand for orthodontic treatment (Oliveira, Tavares, \& Freitas, 2013). However, orthodontic treatment can be a quite uncomfortable experience and may cause pain especially at the initial stage of the treatment. Several factors were found to be associated with the discomfort accompanying orthodontic appliances, such factors include the type of appliance used, amount of force applied, previous experience of pain, emotional changes and the cognitive and environmental aspects (Marques, Paiva, Vieira-Andrade, Pereira, \& Ramos-Jorge, 2014). Patients usually experience pain and discomfort 4 hours after orthodontic appliance insertion, reaching the peak between 12 hours and 3 days after insertion, and then gradually decrease for up to 7 days (Johal, Fleming, \& Al Jawad, 2014; Polat, 2007).

Studies have shown that orthodontic treatment has a potential impact on patients' daily life and may change or restrict their dietary habits (Scheurer, Firestone, \& Bürgin, 1996). This is because chewing and swallowing hard foods can be difficult for patients, and the masticatory ability is reduced at the first 24 hours after insertion of the fixed appliance. However, after 4 to 6 weeks masticatory ability is expected to return to its baseline (Feldmann, 
List, \& Bondemark, 2011). Consequently, to minimize pain and discomfort patients usually tend to follow a soft food diet and decrease their dietary intake (Sandeep et al., 2016). A study predicted that the application of arch wires will result in restraining many types of food which is caused by the loss of pleasure to eat (Marcenes, Steele, Sheiham, \& Walls, 2003). Hence, the patients have to have attention toward their nutrients and consume food that are rich in nutritional values to maintain a good overall health (Sandeep et al., 2016).

A study was conducted in 2016 by Sandeep et al. concluded that, there is marked reduction in weight, BMI, and BMF in the first month after the insertion of orthodontic appliances. Followed by an increased in these parameters at the end of the third month. Unfortunately, this study did not consider any psychological, environmental or dietary changes that could contribute to the weight loss (Sandeep et al., 2016). It is known that orthodontic treatment induces a physical, psychological and emotional stress that reduce nutrient utilization. Therefore, requiring the increase of the individual dietary intake (Ajmera, Tarvade, \& Patni, 2015). Limited food intake or consuming only soft diet will result in decrease of body weight and thus loss of body fat (Sandeep et al., 2016).

Very few studies have evaluated the effect of orthodontic appliances on weight. Previous studies did not consider any confounding factors that may be associated with weight fluctuation. The aim of the current study was to assess and compare the changes in body weight, dietary habits, and pain perception of patient's undergoing orthodontic treatment at the initial stage. The study objectives were met by evaluating the patient's weight at the first visit of orthodontic treatment and compare it to future visits, to assess dietary habits changes of patients during orthodontic treatment, and to determine patients' pain perception throughout the initial stage of orthodontic treatment.

\section{Subjects and Methods}

\subsection{Study Subjects}

Upon obtaining the ethical approval of Institutional Review Board (IRB) of Riyadh Elm University and signature of a consent form, this study was conducted as an observational prospective cohort study to assess patients' changes in body weight, dietary habits, and pain perception undergoing orthodontic treatment at the initial stage attending to orthodontic department clinics at Riyadh Elm University, Riyadh, Kingdom of Saudi Arabia (KSA). This study adhered to the tenets of the Declaration of Helsinki. The weight as well as dietary habits of patients were measured at the initial visit "prior reserving of any the orthodontic treatment" as (T0). Re-evaluation of patient weight, dietary habits, and pain perception were re-assessed on the next visit" after fixed orthodontic appliance bonding" as (T1) one month later. The pain, discomfort, and dietary habits changes were evaluated using a validated questionnaire (Miller et al., 2007) obtained from a study conducted by Miller et al. which was modified to reach the goals of the current study.

\subsection{Data Collection}

The present study was conducted among patients who had undergone non extraction comprehensive orthodontic treatment at orthodontic department of Riyadh Elm University, Riyadh, KSA. Patients who received orthodontic treatment "for the first time" and those who are within the age group of 18-30 years old including both genders were included in the study. Patients who did not consent, who followed a certain diet attempting to lose or gain weight, those with eating disorders such anorexia or bulimia nervosa, those with systemic disease, those who are on medications that causes weight fluctuation such as diuretics or laxatives, and those with syndromes were excluded.

The sample size of "30 adult patients" was determined using openepi website for sample size calculation [openepi.com]. A convenient sampling method was used since the participants for this study were selected among the patients who were registered and due for orthodontic treatment at Riyadh Elm University.

\subsection{Statistical Analysis}

The data obtained from patients was entered into Microsoft excel ${ }^{\mathrm{TM}}$. The data was then imported to Statistical Software for Social Sciences (SPSS) Version 23 for statistical analysis. Wilcoxon signed ranks test and Spearman's rho correlation was used. A $p$ value of $\leq 0.05$ was considered as statistically significant.

\section{Results}

The mean (SD) of the subjects was 18.4 (7.38) years and ranging from 11-50 years. All subjects were Saudi nationals. Table 1 shows the demographic and personal characteristics of the subjects. The majority reported sedentary lifestyle $(73.3 \%, \mathrm{n}=22)$. The mean (SD) patient weight at first and second visit of orthodontic treatment was 67.43 (24.42) and 64.98 (22.7) kg respectively. Wilcoxon signed ranks test showed that the difference in the patient weight between first and second visit was statistically significant $(\mathrm{p}<0.05)($ Table 2 and Figure 1$)$. 


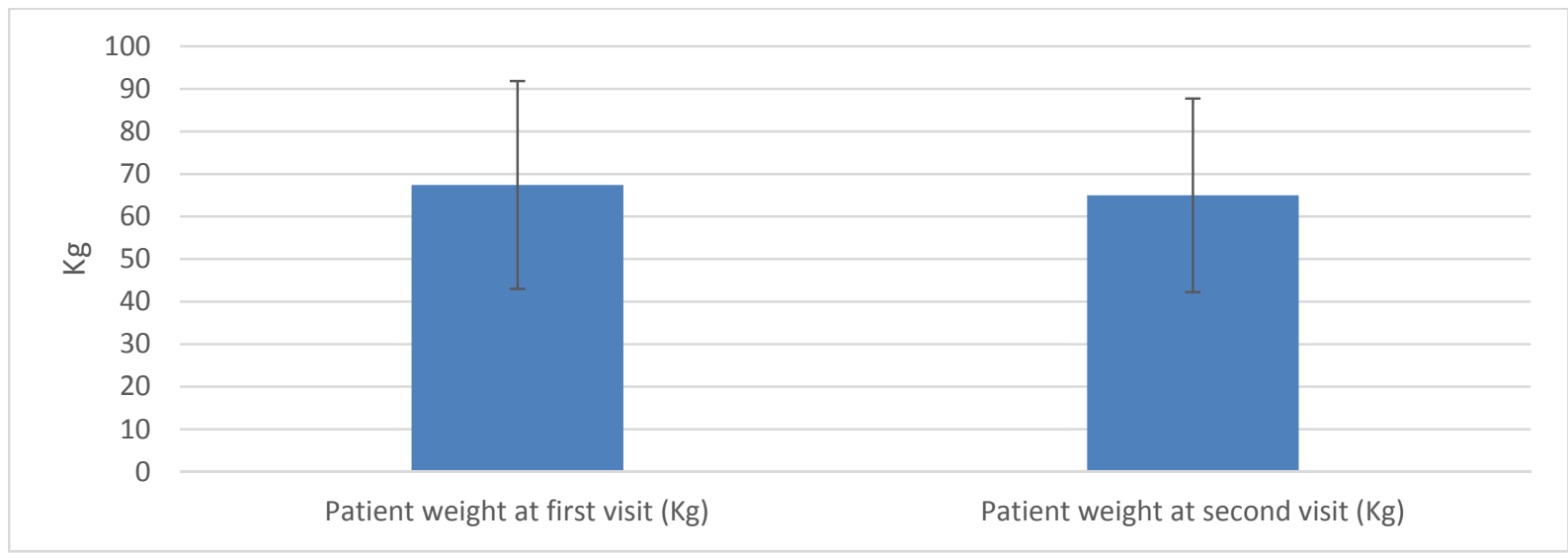

Figure 1. Mean (SD) patient weight at first and second visit

Table 1. Demographic characteristics

\begin{tabular}{llll}
\hline & & $\begin{array}{l}\text { Frequency } \\
(\mathrm{n})\end{array}$ & $\begin{array}{l}\text { Percent } \\
(\%)\end{array}$ \\
\hline \multirow{2}{*}{ Gender } & Male & 16 & 53.3 \\
& Female & 14 & 46.7 \\
\hline \multirow{4}{*}{ Occupation } & Intermediate & 13 & 43.3 \\
& High school & 7 & 23.3 \\
& College student & 6 & 20.0 \\
\multirow{2}{*}{ Lifestyle } & Employed & 4 & 13.3 \\
& Active lifestyle & 8 & 26.7 \\
\hline
\end{tabular}

Table 2. Comparison of mean patient weight $(\mathrm{kg})$ between first and second visit

\begin{tabular}{llllll}
\hline & Mean & Standard Deviation & Minimum & Maximum & $\mathrm{p}$ value \\
\hline Patient weight at first visit $(\mathrm{Kg})$ & 67.43 & 24.42 & 32.40 & 119.50 & $0.000^{*}$ \\
Patient weight at second visit $(\mathrm{Kg})$ & 64.98 & 22.77 & 31.60 & 117.0 & \\
\hline
\end{tabular}

(Figure 2) shows dietary habits changes and pain perception of patients during and throughout the initial stage of orthodontic treatment. Just over half the patients reported that they always had troubles biting or chewing any kinds of food such as firm meat or apple $(51.7 \%, \mathrm{n}=15)$. On the other hand, $51.7 \%(\mathrm{n}=15)$ never used any medication to relieve pain or discomfort from around your mouth, followed by $41.4 \%(\mathrm{n}=12)$ never felt uncomfortable eating in front of people because of problems in your teeth or orthodontic appliance, and $37.9 \%$ $(n=11)$ never had teeth sensitive to hot, cold or sweets. 
Did you limit the kinds or amount of food you eat.. Did you have troubles biting or chewing any kinds of.. Were you able to swallow comfortably? Were you able to eat anything without feeling... Did you use any medication to relieve pain or... Did you feel uncomfortable eating in front of people...

Were your teeth sensitive to hot, cold or sweets? Did your orthodontic appliance causes discomfort to...

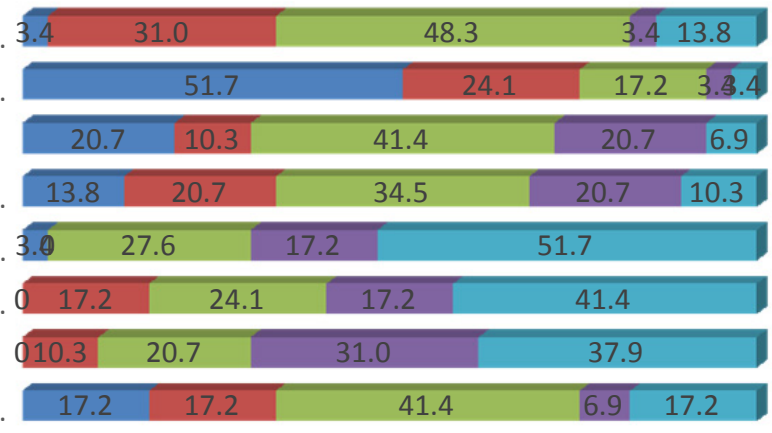

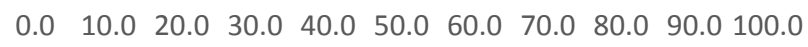

Percentage

always $\square$ Often Sometimes $\square$ Seldom $\quad$ Never

Figure 2. Dietary habits changes and pain perception of patients during and throughout the initial

The mean difference of weight among males and females between first and send visit was $2.61 \mathrm{~kg}$ and 2.17 respectively (Figure 3). However, this difference was statistically not significant ( $p>0.05$ ). Furthermore, the mean difference of weight among active and sedentary lifestyle between first and send visit was $1.88 \mathrm{~kg}$ and 2.66 respectively (Figure 4). Moreover, this difference was statistically not significant $(p<0.05)$. Spearman's rho showed a negative correlation between weight change and items 1, 2, 5, 6, 7, and 8. However, statistical significance was found only with item 5 . Furthermore, positive correlation was found between weight change and items 3 and 4 . However, statistical significance was found only with item 4 (Table 3).

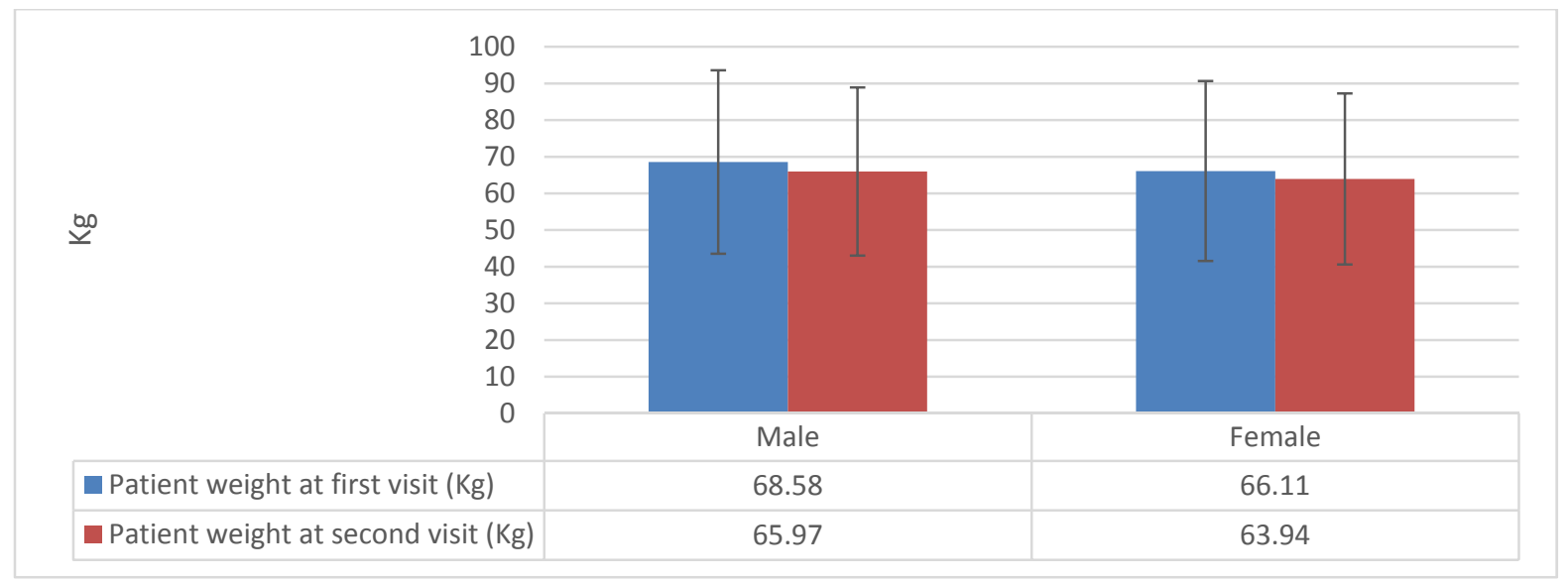

Figure 3. Comparison of mean (SD) patient weight at first and second visit by gender 


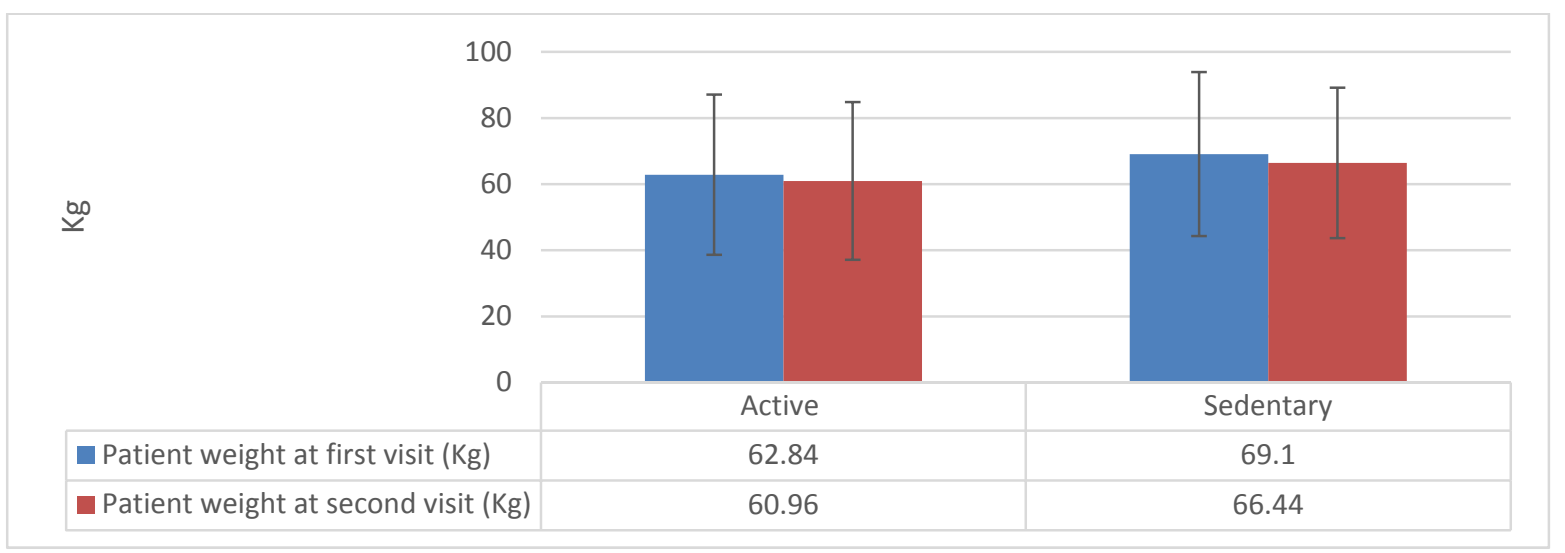

Figure 4. Comparison of mean (SD) patient weight at first and second visit by lifestyle

Table 3. Relationship between dietary habits changes and pain perception of patients during and throughout the initial stage of orthodontic treatment and weight changes

\begin{tabular}{llc}
\hline Items & rho & p value \\
\hline $\begin{array}{l}\text { 1. Did you limit the kinds or amount of food you eat because of problems mouth, teeth or } \\
\text { orthodontic appliance? }\end{array}$ & -0.344 & 0.068 \\
2. Did you have troubles biting or chewing any kinds of food such as, firm meat or apples? & -0.277 & 0.146 \\
3. Were you able to swallow comfortably? & 0.172 & 0.374 \\
4. Were you able to eat anything without feeling discomfort? & 0.464 & $0.011^{*}$ \\
5. Did you use any medication to relieve pain or discomfort from around your mouth? & -0.532 & $0.003^{*}$ \\
6. Did you feel uncomfortable eating in front of people because of problems in your teeth or & -0.298 & 0.116 \\
orthodontic appliance? & -0.283 & 0.137 \\
7. Were your teeth sensitive to hot, cold or sweets? & -0.203 \\
8. Did your orthodontic appliance causes discomfort to your cheeks, tongue or lips? & 0.291 \\
\hline
\end{tabular}

* Statistical significance.

\section{Discussion}

Orthodontic treatment usually recommends to eat soft food to prevent associated pain and discomfort, difficulty in chewing, and the risk of appliance breakage on eating hard food (Sandeep et al., 2016). Orthodontic management is said to create a physical, physiologic, and emotional stress which causes an increases in nutrient utilization which raises the individual's body nutritional requirement (Ajmera et al., 2015).

Our study aimed to assess and compare the changes in body weight, dietary habits, and pain perception of patient's undergoing orthodontic treatment at the initial stage.

This present study recorded a certain weight loss among the participants with the mean (SD) patient weight at first and second visit of orthodontic treatment was 67.43 (24.42) and 64.98 (22.70) $\mathrm{kg}$ respectively. This is in comparison to the study in India Sandeep et al. which found definite weight reduction among participants in the first month. In this study, weight was measured at three different intervals but in our study no specific time intervals of weight measurements was maintained (Sandeep et al., 2016).

Our study showed weight changes among both male and female participants undergoing orthodontic treatment. Weight reduction from the first visit to the second visit of orthodontic procedures was recorded. The mean difference of weight among males between first and second visit was $2.61 \mathrm{~kg}$ and among females between first and second visit was 2.17 respectively. However, this difference was statistically not significant ( $p>0.05)$. There was slightly more weight loss among the males $(0.44 \mathrm{~kg})$ in comparison with the females. A previous showed results similar to the present study with weight loss more marked in males in the first month in comparison to the females with a mean decrease in weight of $1.44 \mathrm{~kg}$ and $1 \mathrm{~kg}$ among females also in the first 1-month period. Pain after the initial onset of treatment with arch wires which causes difficulty in eating regular food which takes time to get 
accustomed may be the cause of weight loss (Sandeep et al., 2016).

Another study by Soni et al. in 2013 was in similar line to our study which reported the weight loss among the male participants to be relatively higher $(55.08 \mathrm{~kg}, 54.2 \mathrm{~kg})$ than the female $(62.6 \mathrm{~kg}, 60.3 \mathrm{~kg})$ participants measures in between a month interval from the orthodontic treatment (Soni, Sharma, \& Patel, 2013). Pain and discomfort of varying degree is usually experienced by patients undergoing fixed treatment with pain intensity being maximum during the initial week following placement of the appliances which reduces later (Bergius, Berggren, \& Kiliaridis, 2002; Sergl, Klages, \& Zentner, 1998). In our study only $31 \%$ participants used medication for pain while $51.7 \%$ never used any medication to relieve pain or discomfort from the treatment. Different orthodontic treatments such as separator placement, arch wire placement and activations, application of orthopaedic forces, and debonding may couse more discomfort and pain than the others (Sandeep et al., 2016). However, In a study it was reported that only $30 \%$ of the participants used analgesics which is similar to our study (Abed Al Jawad, Cunningham, Croft, \& Johal, 2011).

In the present study it was found that just over half the patients reported that they always had troubles biting or chewing any kinds of food such as firm meat or apple (51.7\%). This is in line with the qualitative study conducted in 2011 where the majority of patients reported difficulty in eating and chewing due to pain and this resulted in eating a softer diet in preference to hard food types (Abed Al Jawad et al., 2011). A study conducted in 2013 also reported difficulty in chewing hard food and felt comfortable with soft food and liquids especially for the initial ten days after the orthodontic treatment also similar to this study (Soni et al., 2013).

This study correlated discomfort when eating to weight loss after orthodontic treatment and found a positive correlation. Patients with discomfort were reported to have weight loss. A negative correlation was recorded among patients who used medication for pain with weight loss. It was found that patients who used medication to relieve pain had weight loss. There was no study found to compare with this present study on the correlation of weight loss with factors associated with dietary changes, pain and discomfort after orthodontic treatment.

\section{Conclusion}

This study confirms the initial loss of weight, pain and discomfort among patients who undergo comprehensive orthodontic treatments. The findings of this study are important among the orthodontic centres and practitioners highlighting the concern of their guidance in structured diet planning and advice after treatment. Further study involving multiple weight measurements in a pre-determined time gap will help in a better comparative assessment of weight change of individuals undergoing orthodontic treatment. This could help in planning a healthier well balanced diet and also address the distress of pain and discomfort of the treatment as they are all interconnected factors.

\section{Competing Interests Statement}

The authors declare that there are no competing or potential conflicts of interest.

\section{References}

Abed Al Jawad, F., Cunningham, S. J., Croft, N., \& Johal, A. (2011). A qualitative study of the early effects of fixed orthodontic treatment on dietary intake and behaviour in adolescent patients. The European Journal of Orthodontics, 34(4), 432-436. https://doi.org/10.1093/ejo/cjr032

Ajmera, A. J., Tarvade, S. S., \& Patni, V. R. (2015). A systematic nutritional and dietary guideline for orthodontic patients. Journal of Orthodontic Research, 3(2), 88. http://www.jorthodr.org/text.asp?2015/3/2/88/150875

Bergius, M., Berggren, U., \& Kiliaridis, S. (2002). Experience of pain during an orthodontic procedure. European journal of oral sciences, 110(2), 92-98. https://doi.org/10.1034/j.1600-0722.2002.11193.x

Borzabadi-Farahani, A. (2011). An insight into four orthodontic treatment need indices. Progress in orthodontics, 12(2), 132-142. https://doi.org/10.1016/j.pio.2011.06.001

Feldmann, I., List, T., \& Bondemark, L. (2011). Orthodontic anchoring techniques and its influence on pain, discomfort, and jaw function - a randomized controlled trial. The European Journal of Orthodontics, 34(1), 102-108. https://doi.org/10.1093/ejo/cjq171

Johal, A., Fleming, P., \& Al Jawad, F. (2014). A prospective longitudinal controlled assessment of pain experience and oral health - related quality of life in adolescents undergoing fixed appliance treatment. Orthodontics \& craniofacial research, 17(3), 178-186. https://doi.org/10.1111/ocr.12044

Marcenes, W., Steele, J. G., Sheiham, A., \& Walls, A. W. G. (2003). The relationship between dental status, food selection, nutrient intake, nutritional status, and body mass index in older people. Cadernos de saude publica, 
19(3), 809-815. https://www.scielosp.org/scielo.php?pid=S0102311X2003000300013\&script=sci_arttext

Marques, L. S., Paiva, S. M., Vieira-Andrade, R. G., Pereira, L. J., \& Ramos-Jorge, M. L. (2014). Discomfort associated with fixed orthodontic appliances: determinant factors and influence on quality of life. Dental press journal of orthodontics, 19(3), 102-107. http://dx.doi.org/10.1590/2176-9451.19.3.102-107.oar

Miller, K. B., McGorray, S. P., Womack, R., Quintero, J. C., Perelmuter, M., Gibson, J., . . Wheeler, T. T. (2007). A comparison of treatment impacts between Invisalign aligner and fixed appliance therapy during the first week of treatment. American Journal of Orthodontics and Dentofacial Orthopedics, 131(3), 302. e301-302. e309. https://doi.org/10.1016/j.ajodo.2006.05.031

Oliveira, P. G. d. S. A., Tavares, R. R., \& Freitas, J. C. d. (2013). Assessment of motivation, expectations and satisfaction of adult patients submitted to orthodontic treatment. Dental press journal of orthodontics, 18(2), 81-87. http://dx.doi.org/10.1590/S2176-94512013000200018

Polat, Ö. (2007). Pain and discomfort after orthodontic appointments. Paper presented at the Seminars in orthodontics. https://doi.org/10.1053/j.sodo.2007.08.010

Sandeep, K. S., Singaraju, G. S., Reddy, V. K., Mandava, P., Bhavikati, V. N., \& Reddy, R. (2016). Evaluation of body weight, body mass index, and body fat percentage changes in early stages of fixed orthodontic therapy. Journal of International Society of Preventive \& Community Dentistry, 6(4), 349. https://doi: 10.4103/2231-0762.186796

Scheurer, P. A., Firestone, A. R., \& Bürgin, W. B. (1996). Perception of pain as a result of orthodontic treatment with fixed appliances. The European Journal of Orthodontics, 18(1), 349-357. https://doi.org/10.1093/ejo/18.1.349

Sergl, H. G., Klages, U., \& Zentner, A. (1998). Pain and discomfort during orthodontic treatment: causative factors and effects on compliance. American Journal of Orthodontics and Dentofacial Orthopedics, 114(6), 684-691. https://doi.org/10.1016/S0889-5406(98)70201-X

Soni, V. K., Sharma, L., \& Patel, P. (2013). Comparative evaluation of changes observed in the weights of patients undergoing fixed orthodontic treatment in Jaipur population. International Journal of Pharmaceutical Science Invention, 2(5), 66-69.

\section{Copyrights}

Copyright for this article is retained by the author(s), with first publication rights granted to the journal.

This is an open-access article distributed under the terms and conditions of the Creative Commons Attribution license (http://creativecommons.org/licenses/by/4.0/). 